\title{
Applied Undergraduate Institutions Based on the CDIO Concept of the "Database Theory and Application" of the Teaching Reform
}

\author{
Jingmei Zhang ${ }^{1, a^{*}}$ and Jigang Zheng ${ }^{2, b}$ \\ ${ }^{1}$ Library of Baoshan College, Baoshan, Yunnan, 678000, China. \\ ${ }^{2}$ Department of Mathmatic,Baoshan College,Baoshan, Yunnan,678000, China. \\ a279619568@qq.com,b6913641@qq.com \\ * The corresponding author
}

\section{Keywords: CDIO; Application type; Course; Teaching reform; Practical ability}

\begin{abstract}
Database Principles and Applications" is a theoretical, practical, innovative highly integrated curriculum, based on the CDIO philosophy of education," learning to do, learning by doing, apply their knowledge for the purpose", there is a theory for teaching out of line with the practice of teaching content and practical application of touch, from the practice teaching reform teaching methods, course feedback mechanism, establish a rational evaluation system.

According to the "national long-term education reform and development plan (2010 - 2020)",the future of China's higher education task to promote college features, establishing the classification system, the implementation of classification management; policy guidance and play a role in the allocation of resources, to guide the reasonable positioning, overcome the homogenization tendency, the formation of the respective school idea and style; do the characteristics at different levels and in different areas, striving for excellence". Curriculum is the basic unit of personnel training system in Colleges and universities, and also the basic carrier of talent training process. Curriculum characteristics determine the characteristics of talent training. In order to cultivate the characteristic talents and cultivate the characteristics of the school, it is necessary to study and cultivate the characteristics of the course. Curriculum characteristics are characterized by the combination of courses, namely, the characteristics of the macro level curriculum system, and the characteristics of curriculum teaching, namely, the characteristics of a single curriculum at the micro level.

$\mathrm{CDIO}$ is the latest achievements of international engineering education reform in recent years, CDIO (Conceive), design concept (Design),(Implement) and operation (Operate), it is the Massachusetts Institute of Technology and the Swedish Royal Institute of technology and other 4 universities under the background of global economic integration, after 4 years of research and the results obtained, it is "doing" and "focuses on project teaching and learning" and abstract expression based on[1].It takes the product development to the product operation life cycle as the carrier, lets the student take initiative, the practice, the curriculum organic connection way study engineering. CDIO training outline engineering graduates are divided into four levels of interpersonal ability and team ability of engineering system engineering basic knowledge, personal ability, and to cultivate the comprehensive program to enable students to achieve the intended target in the four aspects. The concept of CDIO not only inherited and developed in Europe and the United States for more than 20 years of reform of engineering education concept, more important is to put forward a system of training, ability of the full implementation of the 12 standards for evaluation and inspection.
\end{abstract}

At present, there are many studies on the characteristics of the curriculum system of application-oriented universities, which have formed a wealth of research results, and the teaching design based on a single course is a subject that needs further exploration[2]. At present, colleges and universities not only set up "database principle and application" course in computer specialty, but also set up this course in non computer science and engineering specialty. The National Computer Rank Examination (NCRE), the National Computer Application Technology Certificate (NIT), the national various areas of the university students computer grade examination, the National Mathematical Modeling Contest will be included in the scope of database technology and application of comprehensive examination. Because of the "database principle and application" is a 
theoretical, practical and innovative comprehensive curriculum, often the actual teaching effect is not very ideal, this article launches the analysis in order to solve the problem on related issues, put forward the teaching plan better.

\section{Orientation of Application Oriented Universities}

China's higher education consists of two series, three levels and four types, namely full-time education and continuing education two series, three levels of graduate education, undergraduate education and higher occupation education, research university, teaching and Research University, teaching university and Career Academy higher four types. The international classification of educational standards approved by UNESCO has divided higher education into two stages. The first stage is equivalent to the education of junior college, undergraduate and postgraduate, and the second stage is equivalent to the doctoral education[3]. The first stage is divided into two categories: $5 \mathrm{~A}$ and $5 \mathrm{~B}$,class 5 is academic theory, and $5 \mathrm{~B}$ is practical and technical. The $5 \mathrm{~A}$ class is divided into 5A1 and 5A2 two categories,5A1 is divided into professional requirements according to the subject, mainly for the cultivation of talents, $5 \mathrm{~A} 2$ is divided into a professional industry according to the requirements, the main training specialized personnel from all walks of life. Applied undergraduate colleges should be located on the level of 5A2, the fundamental purpose of the development of applied undergraduate education is to train practical talents in a large number of "going down, stay useful" for local economic construction and social development.

Judging from the current situation, application-oriented universities should be regional, largely in order to adapt and promote the development of local society and economy, combined with the formation or upgraded to, is generally applied senior specialized grassroots oriented, for the production of the first line of the training and serving local economic construction are the main goal and direction of development[4].

Applied undergraduate colleges is not only different from universities, and to focus on the difference between higher vocational practical ability oriented colleges, the goal of running a school and professional settings on the local economic and social development needs, to the applied talents training objectives, to apply research direction for scientific research. This paper studies the talent demand and industrial structure in the region, studies its social characteristics and service space, actively serves the local economy, and realizes the interactive development with the local society. Therefore, according to the type of Applied Undergraduate Colleges positioning themselves in the applied talents, rather than scientific elite culture has certain knowledge, ability and comprehensive quality for production, construction, management, service and other front-line or post group and adapt to the needs of senior applied talents of sustainable development potential.

\section{Problems Existing in the Teaching of Database Principles and Applications}

With the changing hardware environment, the software environment from low-end micro database to high-end commercial database, the teaching hours reduced from 72 to 54 hours or less, the problems and contradictions in teaching are more prominent.

Disconnection between Theory and Practice. Stick to the traditional ideas in teaching, still use "knowledge module sequence theory practice theory" teaching, then introduces the basic principle of database related basic concepts, data model, three stage model, relational algebra database, and then apply these principle are introduced through examples, finally introduces the related theoretical knowledge, i.e.it is based on relational database, using the database management system (DBMS) as the center[5].Because of the basic theory, basic methods and basic technology of the database, the theory is strong and the degree of abstraction is high, which leads the students to feel passive boring, low interest and difficult understanding in the initial theoretical knowledge learning stage. In practice, a solid foundation is not due to lack of theoretical guidance and practice, feel unable to start, resulting in a serious gap between theory and practice, further dampened the enthusiasm of the students, so that the decline in the quality of teaching. Although the students put forward a lot of 
opinions on the teaching methods and teaching quality, most teachers think that the teaching hours are reduced.

The Teaching Content is Divorced from the Practical Application. There are many versions of the course materials, but the basic content is similar to the structure. The proportion of the principle part is too large, involving less specific engineering practice application, and the principle and application of the chapter did not better link. The cases involved in the teaching materials are not consistent before and after, which is not conducive to the guidance of the students' continuous inertial thinking. Because of the long period of teaching materials, some of the theories and techniques are out of date in practice, but some new techniques are not introduced. Because of the relationship between class hours, many teachers use traditional methods of teaching, and rush progress, mainly to tell the main, students in the passive learning position, learning enthusiasm is not high.

Lack of Perfect Examination System. Assessment is an effective way to test teaching results and an important means. It plays an important guiding role in students' learning and teacher teaching. Different examination methods can stimulate students' different learning motivation." Database principle and application" is a theoretical and practical course, the traditional examination mode is usually in the final examination results as the main theory basis for the final score of the students, causing students to pass the exam, do not pay attention to improve their ability to complete the task of teaching teachers only teach, do not pay attention to cultivate the comprehensive ability of students[6]. The phenomenon of breaking away from the teaching rules and training objectives has seriously hindered the development of the course "Database Principles and applications".

\section{Reform in Education}

Strengthening Practice Teaching and Paying Attention to Ability training. Increase the number of the original knowledge validation experiments, set up a set of knowledge validation, skills training and ability training as one of the unit experiment program, and the student's experimental report as part of the final exam scores. After the introduction of these reform measures and reform methods, students not only actively and conscientiously carry out experiments in class, but also continue to delve into and discuss thoroughly after class, and write experimental reports. Through the exercise of these experiments, students' enthusiasm for learning theoretical knowledge has also been improved, practical ability and innovation ability have been strengthened.

Reasonable collocation of experimental items, and appropriate increase in class practice class hours and extracurricular practice class hours, experimental content should cover the theory of relations, design theory, database management. The course gives each student a comprehensive application, students are required to strictly according to database design steps, namely the database needs analysis database concept structure design database logical structure design and physical design of database to the database implementation and maintenance requirements detailed data flow diagram data dictionary, E-R map elationship model.

Reform of Teaching Methods. The CDIO engineering training objectives to further establish the status of the curriculum and teaching objectives; take lectures, seminars and other means of teaching, students can be divided into groups based on class teaching units, group practice unit. Reform the evaluation method of curriculum, and distribute the results in the whole study and training process. The teaching content, teaching order, teaching methods and methods are effectively decomposed. In teaching methods, the rational use of multimedia (such as using Flash, Video and other materials) in the classroom to do a presentation.

Establishing Curriculum Feedback Mechanism. The whole teaching activity is decomposed into several links to shorten the feedback cycle, so that the teaching quality and effect can be monitored in time. In a classroom of 2 hours of teaching activities for example, need to arrange the course introduction mechanism, usually using anchor method or problem based learning method to guide the students' thinking, to provide time for discussion and thinking about 5-10 minutes, and then explore and solve the problems of [7].All in the teaching activities of the feedback assessment 
can make different difficulty and learning objectives according to the students' level of content of course should be different in the results included in the results, can expect high students can be arranged with innovative or probing questions, the weighted coefficient is 1.1 ; but the result is not very high expectations of the students you can choose the scheme improved topic, weighted coefficient is 0.9 .

Establishing a Scientific and Reasonable Assessment System. In addition to the theoretical assessment of students, we should pay attention to the students' usual learning process assessment and practical ability assessment, to avoid the "high score, low energy" phenomenon. Can make full use of cyber source, so that students will work on time or experimental stage results submitted to the teaching website, which not only can obtain the result of students, also can timely and accurately understand the process of students. It is helpful for teachers to evaluate students objectively, comprehensively and comprehensively; it is helpful to urge students to study and eliminate plagiarism, so as to prevent students from downloading a program at last. In the study of exploratory experiments, even failed experiments may also achieve higher experimental results, mainly on the basis of the evaluation is to see whether the students from the experimental process of the correct use of the basic knowledge and comprehensive application ability, thus to understand the process of students is very necessary.

The evaluation of students' CDIO ability is a specific measure of the students' achievement in the CDIO teaching method, and usually the classroom teaching is evaluated by the teachers. Effective evaluation should adopt different methods to measure students' professional knowledge, personal ability, team cooperation ability and system analysis ability. CDIO method pays attention to the cultivation of ability, and integrates it into the curriculum and teaching practice, and effective evaluation process is necessary. In the evaluation of students' ability to master professional knowledge, we should take the method of combining written test and experiment, while the evaluation of the design and application of comprehensive ability should take the assessment of students' design works. Using a variety of evaluation methods can be applied to a wider range of teaching methods, increase the reliability and effectiveness of evaluation data and evaluate students' learning effect reasonably and scientifically.

\section{Summary}

CDIO is an inclusive reform program, and there is no standard suitable for the teaching of various majors. The concept of CDIO education into the "database principle and application" in the course of teaching, teaching methods, practical cases, problem driven projects, can let students in mastering the basic knowledge, deepen their professional skills, enhance their practical ability, and strengthen the team cooperation ability, to provide students with a suitable method lifelong learning, learning to do, doing what is beneficial to cultivate high-quality talents.

\section{References}

[1] Yang Ren,Xie Hai-ying.Mathematics Experiment Curriculum Teaching Reform Based on CDIO Education idea[J].Research and Exploration in Laboratory,2012,31(4):121-123.

[2] Qian Dong-mei.Research on teaching reform of database principle and application course in application oriented Universities[J].Science \& Technology Vision,2012(13):91-92.

[3] Wu Zhong-quan.The personnel training identification and construction of newly-built colleges-On the practical training[J].Journal of HeBei Normal University,2009,11(10):49-54.

[4] Huang Hui, Ding Li-ping.On the orientation of application oriented Universities[J].JiangSu Higher Education,2012(5):67-68.

[5] Huang Decai,Chen Qingzhang,ancient Hui,qian can,Lv Huiqiang.Curriculum reform and practice of database principle and its application centered on teaching material construction[J].Computer Education,2008(8):139-140.

[6] $\mathrm{Wu}$ Qi.Teaching reform of database principle and Application[J].Computer Learning,2009(6):95-96. 
[7] Hu Xiong-xin, Yao Yuan, Gao Hongli. Analog Electronic Technique Teaching Architecture Based on CDIO Model [J].Journal of EEE,2008,30(4):106-108. 